\title{
Reproductive Risk Factors Differ Among Breast Cancer Patients and Controls in a Public Hospital of Paraiba, Northeast Brazil
}

\author{
Gibran Sarmento de Almeida ${ }^{1}$, Layze Amanda Leal Almeida ${ }^{2}$, Gilmara Marques \\ Rodrigues Araujo ${ }^{3}$, Mathias Weller ${ }^{1 *}$
}

\begin{abstract}
The incidence and mortality rates of breast cancer in Northeast Brazil are increasing and little is known about prevailing reproductive factors contributing to this increase. A case-control study was conducted in a public hospital of Campina Grande, state of Paraíba, including 81 women with diagnosed invasive breast cancer and 162 age matched $( \pm 5$ years) controls. Binominal logistic regression analysis was applied to estimate odds ratio (OR) and confidence intervals $(C I)$ of risk factors. In this model, age at menarche $\leq 12(\mathrm{OR}=2.120 ; \mathrm{CI}$ : 1.043- 4.308; $\mathrm{p}=0.038)$, single parity $(\mathrm{OR}=3.748 ; \mathrm{CI}$ : 1.459- 9.627; $\mathrm{p}=0.06)$ and reproductive period $>10$ years $(\mathrm{OR}=3.042$; CI: $1.421-6.512 ; p=0.04)$ were identified as independent variables that significantly increased breast cancer risk of parous women. Compared to parous women who never practised breastfeeding, total breastfeeding time $>24$ months decreased the risk of breast cancer $(\mathrm{OR}=0.258 ; \mathrm{CI}: 0.084-0.787 ; \mathrm{p}=0.017)$. The results indicated that modifiable reproductive factors contribute to breast cancer risk in women included in the present study. Women's knowledge about factors such as the protective effect of breastfeeding could reduce the risk of breast cancer.
\end{abstract}

Keywords: Breast cancer - epidemiology - reproduction - risk factors - Northeast Brazil

Asian Pac J Cancer Prev, 16 (7), 2959-2965

\section{Introduction}

Breast cancer is the most common malignancy and the leading cause of cancer-related death among women worldwide (Jemal et al., 2011; Benson and Jatoi, 2012; Youlden et al., 2012; Ferlay et al., 2013). Due to prolonged life expectation and lifestyle changes, the global incidence of breast cancer is progressively shifting from developed to developing countries (Benson and Jatoi, 2012; Formenti et al., 2012; Ferlay et al., 2013).

In Brazil, the National Institute of Cancer (INCA) expected 57,120 new cases of breast cancer for the year 2014 (INCA, 2014). In the years between 2012 and 2014, the incidence of breast cancer increased from 52 to 56 cases per 100 thousand women (INCA, 2012; INCA, 2014). In Brazil, the North-eastern region shows the highest increase of breast cancer (INCA, 2012; INCA, 2014). The mortality rate of breast cancer decreased and stabilized between the years 1994 and 2009 in the Southeastern and Southern regions of Brazil, respectively, whereas it increased $5.3 \%$ in the North-eastern region (Freitas-Junior et al., 2012). Increased live expectation and low mammography coverage may contribute to increase the incidence and mortality rate in this region (Viacava et al, 2009; Gebrim et al., 2006; IGBE, 2014). Furthermore, the register praxis of breast cancer in hospitals may have been improved.

Factors such as lifestyle and reproductive patterns may also increase the risk of breast cancer in North-eastern Brazil (Paiva et al., 2002; Souza-Pinho et al., 2007; Leite de Lima et al., 2008; Inumaru et al., 2012). It has been well established in literature that modified reproductive patterns towards delayed childbearing, low parity and short breastfeeding time increase the risk of breast cancer (Balasubramaniam et al., 2013; Hartz and He, 2013; Li et al., 2013; Hosseinzadeh et al., 2014; Lee et al., 2014; Namiranian et al., 2014; Yeo et al., 2014;). Previous studies have also shown a positive association between risk of breast cancer and early age at menarche and older age at menopause (Ghiasvand et al., 2012; Islam et al., 2012; Bhadoria et al., 2013; Tazhibi et al., 2014; Yeo et al., 2014).

Lifestyle-related characteristics such as overweight, obesity, increased body mass index (BMI) and lack of physical exercise have also been identified as risk factors that may increase the risk of breast cancer (Lodha et al., 2011; Alegre et al., 2013; Hartz and He, 2013; Kann et al., 2014; Namiranian et al., 2014; Yeo et al., 2014). Alcohol consumption and smoking were also positively associated with increased risk of breast cancer (Hosseinzadeh et al., 
Gibran Sarmento de Almeida et al

2014; Namiranian et al., 2014; Qian et al., 2014; Yeo et al., 2014). The consumption of fruits was identified to have a protective effect, while poor dietary habits and use of oils with predominant saturated fats were associated with increased risk of breast cancer (Alegre et al., 2013; Balasubramaniam et al., 2013; Hosseinzadeh et al., 2014; Yeo et al., 2014). Dietary patterns can also have protective effects: A recent study has shown decreased risk of breast cancer among women who make use of Spanish Mediterranean diet, with a more pronounced protective effect against triple-negative breast cancer compared to other molecular subtypes (Castello et al., 2014). Finally, family history of breast cancer, history of abortion and oral conceptive use were also associated with increased risk of breast cancer (Islam et al., 2012; Yanhua et al., 2012; Bhadoria et al., 2013; Elkum et al., 2014; Hosseinzadeh et al., 2014; Tazhibi et al., 2014).

Previous case-control studies with Brazilian populations have shown that diet, family history, physical activity, overweight, use of oral contraceptives and reproductive factors are breast cancer risk factors (Tessaro et al., 2001; Vasconcelos et al., 2001; Paiva et al., 2002; Pietro et al., 2007; Lima et al., 2008; Inumaru et al., 2012). Other studies without control groups and statistical analysis identified diet, family history, physical activity, overweight, use of oral contraceptives, reproductive factors, alcohol, age and socio-economic status as risk factors (Lima et al., 2001; Sclowitz et al., 2005; Souza-Pinho et al., 2007; Silva et al., 2009; Matos et al., 2011 and 2010). It is notable that nearly all of these studies referred to data from populations of the Southern, South-eastern and Midwestern regions of the country. To our best knowledge there exist only two studies about risk factors of breast cancer carried out in Northeast Brazil: One exception is a case-control study on diet and other risk factors of breast cancer performed in Joao Pessoa, capital of the state of Paraiba, Brazil (Lima et al., 2008). Furthermore, in the year 1993, Kalache and colleagues performed a case-control study on reproductive risk factors of breast cancer patients in Fortaleza and Recife, capitals of the states of Ceara and Pernambuco, respectively (Kalache et a., 1993).

Despite the ongoing screening mammography program and the increasing incidence and mortality rate of breast cancer in North-eastern Brazil, little is known about prevailing risk factors of the disease in populations of this region. Furthermore, there are no studies on breast cancer risk factors of populations from the hinterland of this region. In the state of Paraiba, the mortality rate due to breast cancer increased about $11.9 \%$ during the last decade (Freitas-Junior et al., 2012). In the present case-control study, several reproductive risk factors were analysed in a population from the hinterland state of Paraiba. The aim of this study was to identify main risk factors of breast cancer and to compare results with studies on populations from other regions of Brazil and other countries.

\section{Materials and Methods}

\section{Study population and data collection}

The data sampling protocol was reviewed and approved by the Brazilian National Research Ethics Committee (CAAE plataforma Brasil: 22358113.1.0000.5187). Written informed consent was obtained for this study from each participant. Participants were eligible if diagnosed within 24 months from recruitment with invasive breast cancer and aged 18 years or older. A structured questionnaire was applied for the interview and height and weight were measured to determine the body mass index. Breast cancer patients and controls were interviewed between March and November 2014. The study included 81 women with invasive operable breast cancer diagnosed and treated between 2012 and 2014. Data from breast cancer patients were obtained from the chemotherapy and radiotherapy units of the "Fundação de Assistência da Paraíba" public hospital (FAP) in Campina Grande, Paraíba, Brazil. The FAP hospital is a reference hospital of the region that receives mainly low-income patients. Campina Grande is located in the hinterland of this state, about $120 \mathrm{~km}$ away from the state capital, Joao Pessoa, with a population of about 385.276 (2010) inhabitants (IGBE, 2014).

For each case, two controls were included in the study. All 162 controls were free of any type of cancer, heart disease or diabetes. They were randomly recruited from public health service centres of Campina Grande. Most of the controls recruited from public health service centres sought these services because they caught cold, were treated for fractures or sprains, back pain, and other diseases such as skin, eye, laryngological.

\section{Statistical analyses}

Data were age adjusted: For each patient, two controls of same age $\left( \pm 5\right.$ years) were sampled. Chi-Square $\left(\chi^{2}\right)$ test and T-test were performed on GraphPad Prism ${ }^{\circledR}$ software version 6 (La Jolla, CA). Chi-Square $\left(\chi^{2}\right)$ test was applied to compare categorized variables. T-test was applied to compare continuous parametric variables of age, obesity and weight.

Binominal logistic regression was performed using SPSS STATISTICS ${ }^{\mathrm{TM}}$ software (SPPS; IBM company; version 17). Significant variables of univariate regression analysis were used for binominal regression modeling. Variables with significance level less than 0.2 in the univariate analysis were entered to the model. Then, variables with significance level less than 0.05 were kept in the model. Backward selection method was used when significant variables in the model were selected. The final model was tested for fitness using the Hosmer-Lemeshow goodness of fit test. Results were presented as adjusted odd ratios (OR), $95 \%$ confidence interval $(\mathrm{CI})$ and $\mathrm{p}$ value.

\section{Results}

Results of lifestyle risk factors, age and income, compared between breast cancer patients and the control group were summarized in Table 1. The mean age of breast cancer patients and control group was $53.32(\mathrm{~s}=11.22)$ and $53.03(\mathrm{~s}=10.67)$ years, respectively (Table 1$)$. There was no significant difference of age, body mass index, weight, physical activity, smoking, alcohol consumption and income between breast cancer patients and control 
Reproductive risk Factors Differ among Breast Cancer Patients and Controls in Paraíba, Northeast Brazil

Table 1. Comparison of Lifestyle Risk Factors, Age and Income between Breast Cancer Patients and Control Group

\begin{tabular}{|c|c|c|c|c|c|}
\hline \multirow[t]{2}{*}{ Variable } & \multicolumn{2}{|c|}{ Cases $(\mathrm{N}=81)$} & \multicolumn{2}{|c|}{ Controls $(\mathrm{N}=162)$} & \multirow[t]{2}{*}{$P$ value } \\
\hline & Mean & $\overline{\mathrm{SD}}$ & Mean & $\overline{\mathrm{SD}}$ & \\
\hline Age & 53.32 & 11.22 & 53.03 & 10.67 & 0.8445 \\
\hline Body mass index & 27.74 & 5.124 & 28.18 & 4.528 & 0.5002 \\
\hline Weight $(\mathrm{kg})$ & 68.49 & 14.25 & 69.03 & 12.19 & 0.7637 \\
\hline $\mathrm{N}$ & $\%$ & $\mathrm{~N}$ & $\%$ & & \\
\hline \multicolumn{6}{|l|}{ Physical activity } \\
\hline Yes & 46 & 57.50 & 89 & 54.94 & 0.7058 \\
\hline No & 34 & 42.50 & 73 & 45.06 & \\
\hline Missing & 1 & & - & & \\
\hline \multicolumn{6}{|l|}{ Alcohol consumption } \\
\hline No consumption & 52 & 64.20 & 92 & 56.79 & 0.2518 \\
\hline Consumption & 29 & 35.80 & 70 & 43.21 & \\
\hline \multicolumn{6}{|l|}{ Smoking } \\
\hline Never & 40 & 49.38 & 66 & 40.74 & 0.2003 \\
\hline Ever & 41 & 50.62 & 96 & 59.26 & \\
\hline \multicolumn{6}{|l|}{ Income } \\
\hline$\leq 3$ minimum wages & 54 & 84.37 & 146 & 90.12 & 0.2224 \\
\hline$>3$ minimum wages & 10 & 15.63 & 16 & 9.88 & \\
\hline Missing & 17 & & - & & \\
\hline
\end{tabular}

Table 2. Odds ratio (OR) and Confidence intervals (CI) of Reproductive Risk Factors Represented for the 243 Women

\begin{tabular}{|c|c|c|c|c|c|c|}
\hline \multirow[t]{2}{*}{ Variable } & \multicolumn{2}{|c|}{ Case $(\mathrm{N}=81)$} & \multicolumn{2}{|c|}{ Control $(\mathrm{N}=162)$} & \multirow[t]{2}{*}{ OR $(95 \% \mathrm{CI})$} & \multirow[t]{2}{*}{ P value* } \\
\hline & $\mathrm{N}$ & $\%$ & $\overline{\mathrm{N}}$ & $\%$ & & \\
\hline \multicolumn{7}{|c|}{ Age at menarche- all women } \\
\hline$>12$ years & 49 & 62.02 & 118 & 73.29 & 1 & 0.076 \\
\hline$\leq 12$ years & 30 & 37.98 & 43 & 26.71 & $1.680(0.947-2.980)$ & \\
\hline Missing & 2 & & 1 & & & \\
\hline \multicolumn{7}{|c|}{ Age at menarche- only parous women } \\
\hline$>12$ years & 38 & 58.46 & 110 & 74.32 & 1 & 0.022 \\
\hline$\leq 12$ years & 27 & 41.54 & 38 & 25.68 & $2.057(1.111-3.808)$ & \\
\hline Missing & 2 & & 1 & & & \\
\hline \multicolumn{7}{|c|}{ Number of children } \\
\hline$\geq 2$ & 53 & 65.44 & 131 & 80.86 & 1 & 0.027 \\
\hline 1 & 14 & 17.28 & 18 & 11.11 & $1.922(0.892-4.143)$ & 0.095 \\
\hline Nuliparity & 14 & 17.28 & 13 & 8.03 & $2.662(1.173-6.041)$ & 0.019 \\
\hline \multicolumn{7}{|c|}{ Age at first gestation } \\
\hline$\leq 20$ & 18 & 27.27 & 56 & 37.84 & 1 & 0.142 \\
\hline $21-29$ & 39 & 59.09 & 82 & 55.40 & $1.480(0.770-2.845)$ & 0.249 \\
\hline$\geq 30$ & 9 & 13.64 & 10 & 6.76 & $2.800(0.984-7.965)$ & 0.054 \\
\hline Missing & 1 & & 1 & & & \\
\hline \multicolumn{7}{|c|}{ Age at last gestation } \\
\hline$<30$ & 18 & 32.14 & 65 & 44.52 & 1 & 0.168 \\
\hline $30-39$ & 29 & 51.79 & 68 & 46.58 & $1.540(0.781-3.038)$ & 0.231 \\
\hline$\geq 40$ & 9 & 16.07 & 13 & 8.90 & $2.500(0.922-6.778)$ & 0.072 \\
\hline Missing & 11 & & 3 & & & \\
\hline \multicolumn{7}{|c|}{ Reproductive period } \\
\hline$\leq 10$ years & 30 & 53.57 & 99 & 67.81 & 1 & 0.061 \\
\hline$>10$ years & 26 & 46.43 & 47 & 30.19 & $1.826(0.973-3.426)$ & \\
\hline Missing & 11 & & 3 & & & \\
\hline \multicolumn{7}{|c|}{ Total breastfeeding time** } \\
\hline Not at all & 10 & 14.93 & 14 & 9.40 & 1 & 0.021 \\
\hline$\leq 12$ & 36 & 53.73 & 55 & 36.91 & $0.916(0.367-2.285)$ & 0.851 \\
\hline $13-24$ & 8 & 11.94 & 21 & 14.09 & $0.533(0.169-1.684)$ & 0.284 \\
\hline$>24$ & 13 & 19.40 & 59 & 39.60 & $0.308(0.12-0.847)$ & 0.022 \\
\hline \multicolumn{7}{|c|}{ Menopause status- all women } \\
\hline Negative & 23 & 28.40 & 63 & 38.89 & 1 & 0.108 \\
\hline Positive & 58 & 71.60 & 99 & 61.11 & $1.605(0.901-2.858)$ & \\
\hline \multicolumn{7}{|c|}{ Menopause status - only parous women } \\
\hline Negative & 18 & 26.87 & 58 & 39.93 & 1 & 0.088 \\
\hline Positive & 49 & 73.13 & 91 & 60.07 & $1.735(0.922-3.266)$ & \\
\hline
\end{tabular}


group (Table 1).

The odds ratios for breast cancer according to the presence of reproductive risk factors were summarized in Table 2. Risk of breast cancer was 1.680 higher $(95 \% \mathrm{CI}$ : $0.947-2.980)$ for women aged $\leq 12$ at menarche $(\mathrm{p}=0.076$; Table 2). If exclusively the 216 parous women were considered, odds ratio increased significantly to 2.057 (95\%CI: 1.111-3.808; $\mathrm{p}=0.022$; Table 2). Parity also showed significant effect on the risk of breast cancer: Compared to women with $\geq 2$ children, nulliparity was associated with a 2.662 times higher risk of breast cancer (95\%CI: 1.173-6.041; $\mathrm{p}=0.019$; Table 2). Women aged $\geq$ 30 years at first gestation showed 2.8 times higher risk of breast cancer compared to the reference group aged $\leq 20$ years (95\%CI: 0.984-7.965; $\mathrm{p}=0.054$; Table 2). Similarly, women aged $\geq 40$ years at last gestation showed a 2.5 times higher risk of breast cancer compared to those aged $<30$ years at last gestation (95\%CI: 0.922-6.778; $\mathrm{p}=0.072$ ). Reproductive period $>10$ years increased 1.826 times the risk of breast cancer (95\%CI: 0.973-3.426; $\mathrm{p}=0.061$; Table 2). Breast feeding had a significant protective effect on the risk of breast cancer: Women with total breastfeeding time $>24$ months showed decreased odds ratio of 0.308 (95\%CI: 0.12-0.847), compared to parous women who had never practised breastfeeding ( $\mathrm{p}=0.022$; Table 2$)$. Positive menopause status of 157 women was associated with a 1.605 times increased risk of breast cancer $(95 \% \mathrm{CI}$ : $0.901-2.858 ; \mathrm{p}=0.108$ ). If only the 216 parous women were considered, odds ratio for positive menopause status was 1.735 (95\%CI: 0.922-3.266; p=0.088; Table 2).

A binominal logistic regression model identified number of children, reproductive period, age at menarche and total breastfeeding time as independent variables that significantly increased the risk of breast cancer (Table 3 ). The model correctly classified $73.10 \%$ of cases. Women aged $\leq 12$ years at menarche showed 2.12 times higher risk of breast cancer (95\%CI: 1.043-4.308) compared to those aged $>12$ years $(\mathrm{p}=0.038$; Table 3$)$. The risk of breast cancer among women with one child was 3.748 times higher compared to those with two or more children (95\% CI: 1.459-9.627; $\mathrm{p}=0.006$; Table 3). Reproductive period $>10$ years led to 3.042 times higher

Table 3. Odds Ratios (OR) and Confidence Intervals (CI) of a Binominal Logistic Regression Model Represented for the 216 Parous Women

\begin{tabular}{|c|c|c|}
\hline Variable & OR $(95 \%$ CI $)$ & $\mathrm{P}$ value* \\
\hline \multicolumn{3}{|c|}{ Age at menarche } \\
\hline$>12$ & 1 & 0.038 \\
\hline$\leq 12$ & $2.120(1.043-4.308)$ & \\
\hline \multicolumn{3}{|c|}{ Number of children } \\
\hline$\geq 2$ & 1 & 0.006 \\
\hline 1 & 3.748 (1.459- 9.627) & \\
\hline \multicolumn{3}{|c|}{ Reproductive period } \\
\hline$\leq 10$ years & 1 & 0.004 \\
\hline$>10$ years & $3.042(1.421-6.512)$ & \\
\hline \multicolumn{3}{|c|}{ Total breastfeeding time** } \\
\hline Not at all & 1 & \\
\hline$\leq 12$ & $0.515(0.187-1.418)$ & 0.199 \\
\hline $13-24$ & $0.633(0.184-2.175)$ & 0.468 \\
\hline$>24$ & $0.258(0.084-0.787)$ & 0.017 \\
\hline
\end{tabular}

2962 Asian Pacific Journal of Cancer Prevention, Vol 16, 2015 risk of breast cancer (95\%CI: 1.421-6.512; $\mathrm{p}=0.004$; Table $3)$. Breastfeeding time $>24$ months led to decreased odds ratio of 0.258 (95\% CI: 0.084-0.787), compared to parous women who had never practised breastfeeding $(\mathrm{p}=0.017$; Table 3).

\section{Discussion}

Hormonal changes triggered by hormones chorionic gonadotropin, progesterone and estrogen modify proliferation and differentiation of breast tissues during pregnancy, breastfeeding and also at menarche (Kobayashi et al., 2012). Early age at menarche is believed to increase the risk of breast cancer due to the increased number of mammary stem cells that accumulate DNA damage since initiation of pupertal development (Kobayashi et al., 2012). Results of the present study revealed that age at menarche $\leq 12$ was an independent risk factor. Parous women aged $\leq 12$ at menarche were more than 2 times likely to have increased risk of breast cancer. There is an agreement with previous studies that revealed a positive association between early age at menarche and risk of breast cancer (Bhadoria et al., 2013; Li et al., 2013; Yeo et al., 2014). In contrast, two studies from Malaysia and Brazil showed that early age at menarche did not significantly contribute to increased risk of breast cancer (Mohd Razif et al., 2011; Lima et al., 2008).

Parity is one of the most well-established modifiable factors involved in breast cancer in women (Albrektsen et al., 2005). The risk of women aged over 25 years is immediately increased after parturition due to inflammatory processes that occur in breast tissues during postpartum involution (Albrektsen et al., 2005; Kobayashi et al., 2012). Despite this initial increase, the overall lifetime risk of parous women remains significantly reduced (Albrektsen et al., 2005). A recent study indicated that pregnancy induces the differentiation of mammary stem and progenitor cells by the down-regulation of Notch and Wnt signalling (Meier-Abt et al., 2013). This in turn, may protect against malignancy of undifferentiated cells. Present results indicated a significant contribution of nulliparity and low number of children in increasing the risk of breast cancer. Furthermore, parity was identified as an independent variable of a logistic regression model. Recent studies from Asian and European countries, middle east and USA also identified low parity or nulliparity as an independent risk factor of breast cancer (Mohd Razif et al., 2011; Ghiasvand et al., 2012; Islam et al., 2012; Li et al., 2012; Yanhua et al., 2012; Balasubramaniam et al., 2013; Hartz and He, 2013; Li et al., 2013; Mousavi et al., 2013; Lee et al., 2014; Namiranian et al., 2014; Surdyka et al., 2014). Similarly, a previous study from North-eastern Brazil associated low parity with increased risk of breast cancer (Kalache et al., 1993). In contrast, a study carried out in Joao Pessoa including 89 cases of breast cancer and 94 controls did not show significant association between parity and breast cancer (Lima et al., 2008).

Results of the present study indicated that reproductive period of more than 10 years significantly contributed as independent variable to increase the risk of breast cancer. This is in agreement with studies from Finland, 
which showed that prolonged time interval between first and last childbirth increased the risk of breast cancer (Hinkula et al., 2001; Kauppila et al., 2012). A recent study revealed that the prolonged reproductive period of breast cancer patients was associated with increased T-class and metastasis formation (Mousavi et al., 2013).

Breastfeeding represents one of the most wellestablished protective factors of breast cancer (Ursin et al., 2005; Ip et al., 2007). In a meta-analysis of 47 studies carried out worldwide, the protective effect of breastfeeding on breast cancer was reported for pre and postmenopausal women (Colaborative group, 2002). It has been hypothesized that breastfeeding performs its protective effect through differentiation of breast tissues and reduction of the lifetime number of ovulatory cycles (Franca-Botelho et al., 2012). To our best knowledge this is the first time that breastfeeding was identified as a modifiable risk factor of breast cancer in a Brazilian population. Present results indicated that the protective effect of breastfeeding represented an independent variable. Women who had practised breastfeeding for more than 24 month had an odds ratio of 0.258 , compared to parous women who never practised it. This is in agreement with recent studies of different populations that also revealed a protective effect of breastfeeding and the independency of this variable in logistic regression models (Lodha et al., 2011; Li et al., 2012; Yanhua et al., 2012; Bhadoria et al., 2013 Elkum et al., 2014; Hosseinzadeh et al., 2014). In another study, total breastfeeding time was significantly different between controls and breast cancer patients, but represented a dependent variable (Hartz and He, 2013). Studies from Spain and the USA also revealed a specific protective effect of breastfeeding on the aggressive type of triple negative breast cancer (TNBC; Redondo et al., 2012; Li et al., 2013).

Older age at first or last gestation increased the risk of breast cancer among women in the present study. However, this contribution was not significant and did not represent an independent variable. Similarly, age at first childbirth was not identified as a factor that significantly contributed to increase the risk of breast cancer in 89 women from Joao Pessoa, North-eastern Brazil (Lima et al., 2008). In contrast, Kalache and colleagues (1993) identified that both, older age at first and last childbirth increased the risk of breast cancer in women from North-eastern Brazil. The latter study included 509 cases of breast cancer. Outcome variations may be due to differences in sample size and study design. Alternatively, there may also be biological differences between populations: Studies from China, India, Japan and Malaysia indicated that older age at first or last childbirth represents an independent variable that increased the risk of breast cancer (Lodha et al., 2011; Mohd Razif et al., 2011; Islam et al., 2012; Yanhua et al., 2012; Bhadoria et al., 2013). In a study from Iran, age at first childbirth did not independently contribute to the final logistic regression model (Ghiasvand et al., 2012).

Similarly, in the case of variables first and last gestation, women with positive menopause status had higher but insignificant risk of breast cancer. Furthermore, menopause status was not an independent variable in the logistic regression model. In contrast, previous studies identified post-menopause status as an independent variable that increased the risk of breast cancer (Elkum et al., 2014 Hosseinzadeh et al., 2014).

Lifestyle-associated risk factors analysed in this study were not significantly different between controls and breast cancer patients. This may be due to the limited number of data used in this study and could indicate that in the present population, modifiable reproductive variables contributed stronger to increase the risk of breast cancer than lifestyle-associated risk factors. In addition to the low number of data, another limitation of the present study was that all patients included belonged to the same health care centre. As reproductive patterns and ethnic composition vary among Brazilian regions, the results of the present study cannot be extrapolated to other regions of Northeastern Brazil. Therefore, multi-centre studies would be useful to further elucidate the contribution of reproductive factors to the risk of breast cancer.

Present results indicate that reproductive factors contribute to increase the risk of breast cancer in a population of North-eastern Brazil. Future studies should increase the number of patients from different health care centres to confirm present results. A recent study from Northeast Brazil identified an increased percentage of elderly women with TNBC and to date there do not exist Brazilian studies about the association between reproductive risk factors and molecular breast cancer subtypes (De Macedo Andrade et al., 2014).

It will be also important to assess the knowledge of women about the risk of breast cancer linked to these reproductive factors. Information directed to women by public and private health services about protective factors such as longer breastfeeding time could help reducing the risk of breast cancer among women. Knowledge on reproductive risk factors such as low parity could motivate participation on the Brazilian public breast cancer screening program and positively stimulate breast self examination (BSE).

\section{References}

Albrektsen G, Heuch I, Hansen S, Kvale G (2005). Breast cancer risk by age at birth, time since birth and time intervals between births: exploring interaction effects. Br J Cancer, 92, 167-75.

Alegre MM, Knowles MH, Robison RA, O’Neill KL (2013). Mechanics behind breast cancer prevention -focus on obesity, exercise and dietary fat. Asian Pac J Cancer Prev, 14, 2207-12.

Amaro J, Severo M, Vilela S, Fonseca S, Fontes F, La Vecchia $\mathrm{C}$, et al (2013). Patterns of breast cancer mortality trends in Europe. Breast, 22, 244-53

Autier P, Boniol M, La Vecchia C, et al (2010). Disparities in breast cancer mortality trends between 30 European countries: retrospective trend analysis of WHO mortality database. $B M J, \mathbf{3 4 1}, 3620$.

Balasubramaniam SM, Rotti SB, Vivekanandam S (2013). Risk factors of female breast carcinoma: A case control study at Puducherry. Indian J Cancer, 50, 1.

Benson JR, Jatoi I (2012). The global breast cancer burden. Future Oncol, 8, 697-702.

Bezerra de Vasconcelos A, Azevedo G, Mendonca S, Sichieri R (2001). Height, weight, weight change and risk of breast 
cancer in Rio de Janeiro, Brazil. Sao Paulo Med J/Rev Paul Med, 119, 62-6.

Bhadoria AS, Kapil U, Sareen N, Singh P (2013). Reproductive factors and breast cancer: A case-control study in tertiary care hospital of North India. Indian Jo Cancer, 50, 316-21.

Carvalho de Matos J, Pelloso SM, de Barros Carvalho MD (2010). Prevalence of risk factors for breast neoplasm in the city of Maringa, Parana State, Brazil. Rev Latino Am Enfermagem, 18, 352-9.

Carvalho de Matos J. Pelloso SM, de Barros Carvalho MD (2011). Fatores associados a realizacao da prevencao secundaria do cancer de mama no Municipio de Maringa, Parana, Brasil. Cad Saude Publica, 27, 888-98.

Castello A, Pollan M, Buijsse B, Ruiz A, Casas AM, BaenaCanada JM, (2014). Spanish Mediterranean diet and other dietary patterns and breast cancer risk: case-control EpiGEICAM study. Br J Cancer, 11, 1454-62.

Collaborative Group on Hormonal Factors in Breast Cancer (2002). Breast cancer and breastfeeding: collaborative reanalysis of individual data from 47 epidemiological studies in 30 countries, including 50302 women with breast cancer and 96973 women without the disease. Lancet, 360, 187-95.

Da Silva EP, Pelloso SM, de Barros Carvalho MD, de Ornelas Toledo MJ (2009). Exploracao de fatores de risco para cancer de mama em mulheres de etnia Kaingang, Terra Indigena Faxinal, Parana, Brasil, 2008. Cad Saude Publica, 25, 1493-500.

De Macedo Andrade AC, Alberis Ferreira Junior C, Dantas Guimaraes B, et al (2014). Molecular breast cancer subtypes and therapies in a public hospital of Northeastern Brazil. BMC Women's Health, 14, 110.

Di Pietro PF, Medeiros NI, Vieira FGK, Fausto MA, Bello-Klein A (2007). Breast cancer in southern Brazil: association with past dietary intake. Nutr Hosp, 22, 565-72.

Elkum N, Al-Tweigeri T, Ajarim D, et al (2014). Obesity is a significant risk factor for breast cancer in Arab wome. BMC Cancer, 14, 788.

Ferlay J, Steliarova-Foucher E, Lortet-Tieulent J, Rosso S, Coebergh JW, Comber H, et al (2013). Cancer incidence and mortality patterns in Europe: Estimates for 40 countries in 2012. Eur J Cancer, 49, 1374-403.

Fernandes de Souza Pinho V, Silva Freire Coutinho E (2007). Variaveis associadas ao cancer de mama em usuarias de unidades basicas de saude. Cad Saude Publica, 23, 1061-69.

Formenti SC, Arslan AA, Love SM (2012). Global breast cancer: the lessons to bring home. Int J Breast Cancer, 2012, 249501.

Franca-Botelho AC, Carvalho Ferreira M, Franca JL, Luzia Franca E (2012). Breastfeeding and its relationship with reduction of breast cancer: a review. Asian Pac J Cancer Prev, 13, 5327-32.

Freitas-Junior R, Maciel Reis Gonzaga C, Maya Aires Freitas N, Martins E, De Cassia de Maio Dardes R (2012). Disparities in female breast cancer mortality rates in Brazil between 1980 and 2009. Clinics, 67, 731-37.

Gebrim LH, Quadros LGA (2006). Rastreamento do cancer de mama no Brasil. Rev Bras Ginecol Obstet, 28, 319-23.

Geimba de Lima M, Koifman S, Lins Scapulatempo I, et al (2001). Fatores de risco para cancer de mama em mulheres indigenas terena de area rural, estado do mato grosso do sul, Brasil. Cad Saude Publica, 17, 1537-44.

Ghiasvand R, Bahmanyar S, Zendehdel K, et al (2012). Postmenopausal breast cancer in Iran; risk factors and their population attributable fractions. BMC Cancer, 12, 414.

Hartz AJ, He T (2013). Cohort study of risk factors for breast cancer in post menopausal women. Epidemiol Health, 35, 2013003.

Hinkula M, Pukkala E, Kyyronen P, Kauppila A (2001). Grand multiparity and the risk of breast cancer: population-based study in Finland. Cancer Causes Control, 12, 491-500.

Hosseinzadeh M, Ziaei JE, Mahdavi N, et al (2014). Risk factors for breast cancer in Iranian women: a hospital-based casecontrol study in Tabriz, Iran. J Breast Cancer, 17, 236-43.

Instituto Brasileiro de Geografia e Estatistica (IGBE, 2014), Rio de Janeiro.

Instituto Nacional de Cancer (INCA): Estimativa 2012: Incidencia de cancer no Brasil. [http://www.inca.gov.br/ estimativa/2012/]

Instituto Nacional de Cancer (INCA): Estimativa 2014: Incidencia de cancer no Brasil. [http://www.inca.gov.br/ estimativa/2014/]

Inumaru LE, Gomes Duarte Quintanilha MI, da Silveira EA, Veloso Naves MM (2012). Risk and protective factors for breast cancer in midwest of Brazil.J Environ Public Health, 2012, 356851

Ip S, Chung M, Raman G, et al (2007). Breastfeeding and maternal and infant health outcomes in developed countries. Evidence Report Technol Assessment, 153, 1-186.

Islam T, Matsuo K, Ito H, et al (2012). Reproductive and hormonal risk factors for luminal, HER2-overexpressing, and triple-negative breast cancer in Japanese women. Ann Oncol, 23, 2435-41.

Jemal A, Center MM, DeSantis C, Ward EM (2010). Global patterns of cancer incidence and mortality rates and trends. Cancer Epidemiol Biomarkers Prev, 19, 1893-907.

Jemal A, Bray F, Center MM, et al (2011). Global cancer statistics. Ca Cancer J Clin, 61, 69-90.

Jung Sun L, Minkyung O, The Korean Breast Cancer Society (2014). Effects of interval between age at first pregnancy and age at diagnosis on breast cancer survival according to menopausal status: a register-based study in Korea. BMC Women's Health, 14, 113.

Kalache A, Maguire A, Thompson SG (1993). Age at last fullterm pregnancy and risk of breast cancer. Lancet, 341, 33-6.

Kann S, Schmid SM, Eichholzer M, et al (2014). The impact of overweight and obesity on breast cancer: data from Switzerland, so far a country little affected by the current global obesity epidemic. Gland Surgery, 3, 181-97.

Kauppila A, Kyyronen P, Lehtinen M, Pukkala E (2012). Dual effect of short interval between first and second birth on ductal breast cancer risk in Finland. Cancer Causes Control, 23, 187-93.

Kobayashi S, Sugiura H, Ando Y, et al (2012). Reproductive history and breast cancer risk. Breast Cancer, 19, 302-8.

Kruk J (2014). Association between vegetable, fruit and carbohydrate intake and breast cancer risk in relation to physical activity. Asian Pac J Cancer Prev, 15, 4429-36.

Leite de Lima FE, do Rosario Dias de Oliveira Latorre M, de Carvalho Costa MJ, Fisberg RM (2008). Diet and cancer in Northeast Brazil: evaluation of eating habits and food group consumption in relation to breast cancer. Cad Saude Publica, 24, 820-8.

Li CI, Beaber EF, Tang MC, et al (2013). Reproductive factors and risk of estrogen receptor positive, triple-negative, and HER2-neu overexpressing breast cancer among women 20-44 years of age. Breast Cancer Res Treat, 137, 579-87.

Li L, Ji J, Wang J, et al (2012). Attributable causes of breast cancer and ovarian cancer in China: Reproductive factors, oral contraceptives and hormone replacement therapy. Chin J Cancer Res, 24, 9-17.

Meier-Abt F, Milani E, Roloff T, et al (2013). Parity induces differentiation and reduces Wnt/Notch signaling ratio and proliferation potential of basal stem/progenitor cells isolated from mouse mammary epithelium. Breast Cancer Res, 15, 36 . 
Mousavi SM, Försti A, Sundquist K, Hemminki K (2013). Do reproductive factors influence $t, n$, and $m$ classes of ductal and lobular breast cancers? a nation-wide follow-up study. PloS ONE, 8, 58867.

Namiranian N, Moradi-Lakeh M, Kazem S, et al (2014). Risk factors of breast cancer in the eastern Mediterranean region: a systematic review and meta-analysis. Asian Pac J Cancer Prev, 15, 9535-41.

Narod SA (2012). Breast cancer in young women. Nat Rev Clin Oncol, 9, 460-70.

Paiva CE, Sakamoto Ribeiro B, Alvarenga Godinho A, et al (2002). Fatores de risco para cancer de mama em Juiz de for a (MG): um estudo caso-controle. Rev Bras Cancerologia, 48, 231-237.

Razif SM, Sulaiman S, Dietetics PGD, et al (2011). The Contribution of reproductive factors and family history towards premenopausal breast cancer risk in Kuala Lumpur, Malaysia. Med J Malaysia, 66, 220-26.

Qian F, Ogundiran F, Hou N, et al (2014). Alcohol consumption and breast cancer risk among women in three Sub-Saharan African Countries. PloS ONE, 9, 106908.

Ravdin PM, Cronin KA, Howlader N, et al (2007). The decrease in breast-cancer incidence in 2003 in the United States. $N$ Engl J Med, 356, 1670-74.

Redondo CM, Gago-Dominguez M, Ponte SM, et al (2012). Breast feeding, parity and breast cancer subtypes in a spanish cohort. PLOS ONE , 7, 40543.

Sclowitz ML, Baptista Menezes AM, Petrucci Gigante D, Tessaro S (2005). Condutas na prevencao secundaria do cancer de mama e fatores associados. Rev Saude Publica, 39, 340-9.

Sepandi M, Akrami M, Tabatabaee H, et al (2014). Breast cancer risk factors in women participating in a breast screening program: a study on 11,850 Iranian females. Asian Pac J Cancer Prev, 15, 8499-502.

Surdyka JA, Surdyka D, Stanislawek A, Staroslawska E, Patyra KI (2014). Selected breast cancer risk factors and early detection of the neoplasm in women from Lublin region attending screening program in St. John's Cancer Center, years 2005-2006. Ann Agric Environ Med, 21, 792-98.

Tazhibi M, Dehghani M, Babazadeh S, Makkarian F, Tabatabaeian M, Sadeghi M, Rezaei P, Faghihi M (2014). Hormonal and reproductive risk factors associated with breast cancer in Isfahan patients. J Educ Health Promot, 3, 106-10.

Tessaroa S, Beria JU, Tomasi E, Barros AJD (2001). Contraceptivos orais e cancer de mama: estudo de casos e controles. Rev Saude Publica, 35, 32-8.

Ursin G, Bernstein L, Lord SJ, et al (2005). Reproductive factors and subtypes of breast cancer defined by hormone receptor and histology. Br J Cancer, 93, 364-71.

Viacava F, Souza-Junior PRB, Moreira RS (2009). Estimativas da cobertura de mamografia segundo inqueritos de saude no Brasil. Rev Saude Publica, 43, 117-125.

Yanhua C, Geater A, You J, et al (2012). Reproductive variables and risk of breast malignant and benign tumours in Yunnan Province, China. Asian Pac J Cancer Prev, 13, 2179-84.

Yeo W, Lee HM, Chan A, Chan EYY, et al (2014). Risk factors and natural history of breast cancer in younger. Chinese women. World J Clin Oncol, 5, 1097-106. 